\title{
Recovery and recrystallization in commercial purity aluminum cold rolled to an ultrahigh strain
}

Mishin, Oleg; Godfrey, A.; Juul Jensen, Dorte; Hansen, Niels

Published in:

Acta Materialia

Link to article, DOI:

10.1016/j.actamat.2013.05.024

Publication date:

2013

Document Version

Early version, also known as pre-print

Link back to DTU Orbit

Citation (APA):

Mishin, O., Godfrey, A., Juul Jensen, D., \& Hansen, N. (2013). Recovery and recrystallization in commercial purity aluminum cold rolled to an ultrahigh strain. Acta Materialia, 61(14), 5354-5364.

https://doi.org/10.1016/j.actamat.2013.05.024

\section{General rights}

Copyright and moral rights for the publications made accessible in the public portal are retained by the authors and/or other copyright owners and it is a condition of accessing publications that users recognise and abide by the legal requirements associated with these rights.

- Users may download and print one copy of any publication from the public portal for the purpose of private study or research.

- You may not further distribute the material or use it for any profit-making activity or commercial gain

- You may freely distribute the URL identifying the publication in the public portal 


\title{
Recovery and recrystallization in commercial purity aluminum cold rolled to an ultrahigh strain
}

\author{
O.V. Mishin ${ }^{1}$, A. Godfrey ${ }^{2}$, D. Juul Jensen ${ }^{1}$ and N. Hansen ${ }^{1}$ \\ ${ }^{1}$ Danish-Chinese Center for Nanometals, Section for Materials Science and Advanced \\ Characterization, Department of Wind Energy, Technical University of Denmark, Risø \\ Campus, 4000 Roskilde, Denmark \\ ${ }^{2}$ Laboratory of Advanced Materials, School of Materials Science and Engineering, \\ Tsinghua University, Beijing 100084, P.R. China
}

\begin{abstract}
Recovery and recrystallization have been studied in commercial purity aluminum cold rolled to an ultrahigh strain $\left(\varepsilon_{\mathrm{vM}}=6.4\right)$ and isothermally annealed at $300^{\circ} \mathrm{C}$. The deformed material consists of three layers with similar fractions of high angle boundaries (HABs) and similar lamellar boundary spacings, but with different textures and different spatial arrangements of the rolling texture components. Annealing leads initially to a coarsening of the lamellar microstructure, accompanied by a reduction in the HAB fraction. Ex-situ experiments using very short annealing times indicate that these microstructural changes are consistent with a process of coarsening via triple junction motion. The recovery proceeds similarly in the center and subsurface layers, but because of the different initial spatial arrangement of the texture components in these layers, the loss of HABs is significantly greater in the subsurface as compared to the center layer. Further annealing leads to discontinuous recrystallization, which occurs differently in the center and subsurface layers. In the center layer, recrystallization proceeds more rapidly and with a larger frequency of nuclei, resulting in a smaller recrystallized grain size. In contrast, pronounced recrystallization in the subsurface layers is delayed and the recrystallized grain size is larger than in the center. It is concluded that the changes taking place during recovery are very significant in determining the subsequent recrystallization behavior in terms of the final grain size and texture.
\end{abstract}


Keywords: severe plastic deformation (SPD), aluminum, deformation structure, recrystallization, texture

\section{Introduction}

As part of a general effort to optimize the mechanical behavior of metals and alloys, there has been much interest in materials deformed to very high strains. These materials are characterized by a great extent of microstructural refinement, which typically results in high levels of strength [1]. The evolution of the microstructure and texture during annealing of such materials is also of considerable interest, both for scientific and technological reasons. It has, for example, been discussed whether for heavily deformed samples the restoration processes, i.e. recovery and recrystallization, are similar or not to those for metals deformed to conventional strains [2-6]. From a technological perspective a study of annealing behavior is also important since heavily strained metals generally lack ductility, and heat treatments may be required to achieve a balance between high strength and improved ductility in such materials. The restoration processes taking place during annealing of lamellar deformation microstructures are of particular interest here, as the well-defined morphology can provide additional information on the microstructural processes taking place during annealing. For instance, in a previous study of Al-0.13\%Mg deformed to yield a fine-scale lamellar structure, it was noted that extensive coarsening occurred during recovery in the range where the lamellar structure was largely preserved [6].

Recent detailed observations made using transmission electron microscopy and electron backscatter diffraction (EBSD) have provided experimental evidence for microstructural coarsening during annealing of heavily deformed aluminum with a lamellar structure as a result of a process referred to as recovery via triple junction (TJ) motion [7]. The effect of such a process on microstructure and texture evolution during recovery, and on the subsequent recrystallization behavior, has though not yet been reported.

In order to study the changes taking place during annealing of a heavily deformed lamellar microstructure, we investigate commercial purity aluminum rolled to an ultrahigh strain of $\varepsilon_{\mathrm{vM}}=6.4$ [8]. It has been found that this material contains a structure 
consisting of one center layer and two subsurface layers, with each layer covering approximately $1 / 3$ of the sample thickness. The microstructure and texture in each type of layer are very different, in terms of the texture components present, the distribution of symmetry variants and the spatial arrangement of the texture components within each layer. This material allows therefore an investigation of the dependence of recovery and recrystallization on the differences between the microstructure and texture in each layer, and specifically provides an opportunity to consider the following questions: (1) can coarsening via TJ motion rationalize changes taking place during recovery?; (2) is the coarsening process dependent on the local texture?; and (3) to what extent do the changes taking place during recovery affect the subsequent recrystallization behavior? To address these questions, a detailed quantitative analysis of the microstructure and texture evolution during annealing of this heavily rolled material is conducted in the present work.

\section{Experimental}

A hot-rolled $\sim 10 \mathrm{~cm}$ thick plate of aluminum AA1050 was used in this study as the starting material [8]. The plate was partially recrystallized in the as-received condition. In the center layer, defined as the central one third of the sample thickness, the fraction recrystallized was $15 \%$. The fraction of recrystallized material was approximately $50 \%$ in the top and bottom layers beneath the surfaces. These two layers will in the following be termed subsurface layers. Also, crystallographic texture was different in the different layers. The center layer of the plate was characterized by a combination of a pronounced rolling texture and a weak cube texture [8]. Increased intensities of shear texture components were observed in the subsurface layers.

The plate was cold rolled by multiple passes to $\sim 0.4 \mathrm{~mm}$, which corresponds to a total von Mises strain $\left(\varepsilon_{\mathrm{vM}}\right)$ of 6.4. Rolling was carried out unidirectionally, with lubrication, by alternating the top and bottom sides between passes. To avoid significant heterogeneities due to roll-gap geometry [9-12], the $1 / \mathrm{h}$ ratio, where $\mathrm{l}$ is the chordal length of the contact between the rolls and the specimen, and $h$ is the mean sample thickness, was maintained predominantly within the range, 0.5-5 (intermediate draughts [11]), except for the initial $20 \%$ reduction, for which small-draught rolling had to be 
applied due to restricted capacity of the experimental rolling mill. It is pertinent to note that rolling with intermediate draughts and low coefficients of friction typically results in rolling-type textures in the large body of a rolled material with a shear texture restricted to a very thin surface layer $[10,13]$. In the sample studied in the present work, a shear $\{001\}<110>$ component was only revealed by inspecting the immediate (not polished) surface in the rolling plane.

To obtain material in different stages of recovery and recrystallization, the rolled specimens were isothermally annealed at $300^{\circ} \mathrm{C}$ for different periods of time. The samples were investigated in the longitudinal section containing the rolling and normal directions (RD-ND) using backscatter electron (BSE) imaging and EBSD in a Zeiss Supra 35 field emission gun scanning electron microscope. For the EBSD analysis of the cold-rolled material step sizes of 25-30 nm were selected. Larger step sizes were used for studying the annealed samples. The deformed and recovered microstructures were investigated at two different depths: in the center and at 30-130 $\mu \mathrm{m}$ from the immediate surfaces. A critical misorientation angle of $1.5^{\circ}$ was applied for defining crystallites in the EBSD maps and for determining proportions of different boundary types. Thus, low angle boundaries (LABs) in the EBSD maps are defined as those with 1.5-15 misorientations. Boundaries $>15^{\circ}$ are defined as HABs.

Crystallographic orientations were measured throughout the entire sample thickness. Each texture data set was divided in three equal subsets: one representing texture in the center layer and two subsets from the subsurface layers. The data from the two opposite subsurface layers were combined when calculating fractions of different texture components. Fractions of texture components were determined applying a $15^{\circ}$ deviation from the corresponding exact $\{\mathrm{hkl}\}<\mathrm{uvw}>$ orientations. The components analyzed in our work were copper $(\mathrm{Cu})\{112\}<111>$, $\mathrm{S}\{123\}<634>$, brass (Bs) $\{110\}<112>$, P $\{110\}<566>$ and Cube $e_{N D}\{001\}<310>$. Orientations that could be classified as belonging to more than one texture component from this list were ascribed to a nearest component. 


\section{Results}

\subsection{Cold-rolled material}

Large differences are seen between the texture of the center and subsurface layers (Fig.1). The center layer contains a typical rolling-type texture with a combination of the $\mathrm{Cu}, \mathrm{S}$ and Bs components, where the $\mathrm{S}$ component is the dominant texture component (see Table 1). In contrast, in each subsurface layer, the texture is dominated by one of the symmetric variants of a component with the maximum intensity in between the ideal $\{112\}<111>\mathrm{Cu}$ and $\left\{\begin{array}{lll}4 & 11\end{array}\right\}<11118>$ (Dillamore) orientations (Fig.1), as also found in some earlier studies of other Al alloys [14,15]. For simplicity the dominant orientation in the subsurface is considered in our work to belong to the $\mathrm{Cu}$ component.

Both in the center and subsurface, the microstructure is subdivided into broad and narrow texture bands, defined here as regions of a predominantly single texture component (see Fig.2). The spatial distribution of these bands and of the texture components within the bands is however different in each of the layers. In the center layer, the broad bands are mostly of the S component, while in the subsurface layers the broad bands are predominantly composed of a single $\mathrm{Cu}$ component (Fig.2 and Fig.3). These texture bands are subdivided by LABs and HABs forming a lamellar structure (in accordance with many previous observations of cold-rolled aluminum, e.g. [16]). Note that individual texture bands may comprise more than one symmetric variant of the same texture component, thus contributing to a frequent occurrence of HABs within such bands (see Fig.3). As shown in Table 1, volumes with orientations of the Bs-component have the smallest average HAB spacings for both the center and subsurface layers. It is also evident that the $\mathrm{HAB}$ spacing for $\mathrm{Cu}$-oriented bands in the subsurface is considerably greater than for bands of the other texture components, whereas in the center the differences between average HAB spacings for the rolling texture components are less significant.

Despite the differences in the spatial distribution of the rolling texture components, HAB fractions and the average spacing between all boundaries along the ND are similar in the different layers (see Table 1). In each layer characteristic deformation zones [17] are observed around coarse particles (Fig.4). 


\subsection{Evolution of microstructure and texture during annealing}

The changes in microstructure and texture during isothermal annealing at $300^{\circ} \mathrm{C}$ for durations of 1 to 120 minutes have been characterized quantitatively by EBSD examination. Two key microstructural parameters have been chosen to quantify the changes, namely the boundary spacing (for misorientations greater than $1.5^{\circ}$ ) along the $\mathrm{ND}$, and the fraction of $\mathrm{HABs}$ ( $f_{\mathrm{HAB}}$, calculated as the number of boundary misorientations greater than $15^{\circ}$ relative to the number of boundary misorientations greater than $1.5^{\circ}$ ). The variations of each of these parameters, together with the change in crystallographic texture are shown in Figs.5,6, where data for the subsurface and center layers are presented separately.

Based on the shapes of these graphs and the microstructures observed in the EBSD maps, the changes taking place during the isothermal annealing can be divided into recovery (up to 10 minutes) and pronounced discontinuous recrystallization (beyond 10 minutes). Since the recovered microstructure continues to evolve after the onset of recrystallization, some overlap exists between recovery and recrystallization. In the following the evolution of the microstructure and texture during recovery and recrystallization is described in more detail.

\subsubsection{Recovery}

During recovery a continuous decrease in the fraction of HABs is observed in both the center and subsurface layers (Fig.5a). This decrease is accompanied by a large change in the boundary spacing during the first minute of annealing, followed by a much slower coarsening rate (Fig.5b). Although the average boundary spacing along the ND increases from $0.23-0.24 \mu \mathrm{m}$ in the cold-rolled condition to $\sim 0.7 \mu \mathrm{m}$ after $1 \mathrm{~min}$ of annealing, the characteristic lamellar structure formed by cold rolling is still preserved (see Fig.7). Significant development of boundary curvature is seen only in few locations after this short annealing treatment. During further coarsening the lamellar structure is largely retained, though the development of local curvature is seen extensively in both the center and surface regions (Fig.8). The change in the fraction of HABs in the subsurface is greater compared to the center layer (Fig.5a). 


\subsubsection{Nucleation sites}

Analysis of large EBSD maps collected for samples annealed for 1 to 5 minutes reveals signs of the early stages of recrystallization, where it was seen that some crystallites were significantly larger than their neighbors. Such large crystallites can be considered recrystallization nuclei and are observed both within lamellar structures and near coarse particles (see Fig.8). Crystallites growing within lamellar structures typically have orientations of the rolling texture components, whereas large crystallites near coarse particles have various orientations including rolling texture components, P, Cube $\mathrm{ND}_{\mathrm{ND}}$ and "random" orientations. Inspection of BSE images provides evidence that the number of fine particles in the microstructure increased considerably as the duration of annealing increased from 5 to 10 minutes, thus indicating a precipitation reaction.

\subsubsection{Recrystallization}

The differences in the microstructure evolution during recovery between the center and the subsurface cause differences in the recrystallization process in these layers. Example EBSD maps showing the microstructure after annealing at $300^{\circ} \mathrm{C}$ for durations of between 10 and 120 minutes are presented in Fig.9. Recrystallization takes place initially more rapidly in the center layer, where a higher frequency of nuclei is seen (Fig.9a,b). However, after $2 \mathrm{~h}$ annealing, when the sample is almost fully recrystallized, a number of small $(<3 \mu \mathrm{m})$ crystallites separated mostly by LABs are still present in the center. Such crystallites, occupying $0.7 \%$ of the total area in this layer, were considered to be remnants of the coarsened deformation structures in an otherwise recrystallized material [8] and were not taken into account when calculating the average size of recrystallized grains. The average recrystallized grain size is found to be substantially smaller, $13 \mu \mathrm{m}$, in the center than in the subsurface layers, where the average grain size is $\sim 30 \mu \mathrm{m}$ (Fig.9c).

A difference is also seen in the recrystallization texture, where a higher fraction of orientations of the rolling texture is found in the center layer, as compared to the subsurface layer that contains significant fractions of the $\mathrm{P}$ and Cube $_{\mathrm{ND}}$ components (Fig.6). 


\section{Discussion}

The rolling procedure applied in the present experiment resulted in a heavily deformed material with a center layer (comprising approximately 1/3 of the sample volume) dominated by orientations of the S component, and two subsurface layers where the texture in each is dominated by a single $\mathrm{Cu}$ component. Characterization of the boundary spacing, boundary misorientation angles and local texture reveals that the microstructural evolution proceeds in three stages during annealing at $300^{\circ} \mathrm{C}$. An initial period of rapid coarsening is followed by slower coarsening, during which the microstructure recovers, and then by recrystallization, which takes place in a microstructure that has significantly different characteristics compared to those in the asdeformed sample. Additionally, significant differences are seen in the evolution of microstructure and texture in the center and subsurface layers. These differences are discussed in the following by analyzing changes first during coarsening and then during recrystallization.

\subsection{Microstructural changes during short-time annealing}

A key observation is that significant coarsening of the microstructure occurs in both the center and subsurface layers while the microstructure still retains its predominantly lamellar characteristics. A mechanism for such microstructural coarsening has recently been proposed by $\mathrm{Yu}$ et al. [7] based on observations of the motion of Ytype TJs in heavily-rolled aluminum. The process is illustrated schematically in Fig.10, where it is shown how shrinkage of two-sided lamellar volumes proceeds by lateral motion of Y-type TJs, thereby leading to a coarsening of the microstructure. As discussed in Refs [18-23], during grain growth a net force at a Y-type junction will exist if the angles at the TJ are not in equilibrium, and such non-equilibrium angles can arise as a result of TJ drag combined with a curvature driven coarsening process. In a heavily rolled microstructure the angles at Y-type TJs are however inherently non-equilibrated, due to the geometry of the deformation process (which tends to produce lamellar boundaries parallel to the rolling plane). During recovery a net force at individual TJs can therefore 
result in a process of microstructural coarsening that has been found to be associated with a low activation energy [24].

Since the largest change in the average boundary spacing is observed in our work in just the first minute of annealing at $300^{\circ} \mathrm{C}$, it is reasonable to monitor the evolution during this initial period of recovery in more detail. This has been carried out for the subsurface layer, as the changes in both boundary spacing and HAB fraction are most pronounced in this layer (see Fig.5).

To follow the changes during the initial period of fast recovery, a subsurface region was mapped using EBSD in the cold-rolled condition and then the same region was re-mapped after ex-situ annealing at $300^{\circ} \mathrm{C}$ for $20 \mathrm{sec}$ and $1 \mathrm{~min}$ without repolishing. The corresponding EBSD maps for this region are shown in Fig.11. The coldrolled microstructure in this region is characterized by a high fraction of HABs and by a predominance of the Cu-oriented crystallites. It is seen that a large change in the microstructure takes place already within the first 20 seconds of annealing. During this period many small subgrains and narrow lamellae delineated by HABs shrink via TJ motion and disappear, whereas crystallites from broader bands, most of which are $\mathrm{Cu}$ oriented, become coarser. This increases the fraction of the $\mathrm{Cu}$ component and results in a dramatic loss of HABs. In the subsequent 40 seconds (total annealing time of 60 seconds) evolution of the microstructure is slower, with most of the remaining small subgrains surrounded by HABs disappearing during annealing. The net result of these changes is a significant increase in the average boundary spacing in the microstructure that still retains the lamellar form characteristic of a heavily rolled material. Although the microstructure evolution seen on the free surface may quantitatively differ from that in the specimen interior, the ex-situ annealing experiment appears to provide a realistic illustration of the changes taking place during this period of initial rapid coarsening.

To analyze the lamellar coarsening process further, the change in the distribution of boundary spacings along the ND is shown in Fig.12 for both the center and subsurface layers, with the data presented separately for spacings between two adjacent HABs, two adjacent LABs, or for pairs with one LAB and one HAB (“HH”, “LL”, and “LH”). For all distributions the bin size is taken to be approximately $1 / 5$ of the average spacing, so that under a normal (uniform) coarsening process the shape of the distributions should 
remain invariant. The overall shape of the histograms does indeed remain similar, though it can also be seen that the largest change in the low spacing bins (to the left of the peak) occurs for the "HH" subset. The preferential loss of "HH" boundary spacings in the center and subsurface layers can be rationalized in terms of both the higher stored energy of such boundary pairs, and the higher mobility expected for boundaries of high misorientation angle. It can be tentatively concluded from these observations that the slowing down of the coarsening process during further annealing is related primarily to the increase in spacing between the lamellar boundaries rather than to any changes in the misorientation characteristics of the boundaries present.

\subsection{Coarsening via triple junction motion and resulting microstructures}

Based on the microstructural observations, the changes during the process of lamellar coarsening can be described as follows. Initially, coarsening occurs rapidly via TJ motion leading to a large increase in the boundary spacing throughout the sample, with some decrease in the fraction of HABs. Subsequently, in both the center and subsurface layers this process continues at a slower rate with the removal of narrow lamellae.

Due to the differences in the crystallographic orientations and their spatial arrangement in the subsurface and center layers, the coarsening results in different microstructures in each layer. In the subsurface, this process produces a microstructure with a large area fraction of broad bands having orientations from one of the two $\mathrm{Cu}$ texture variants. This consequently results in a large decrease in the fraction of HABs (by the removal of two HABs resulting in the formation of one LAB, see Fig.10). The observed reduction in the fraction of HABs during coarsening is consistent with several previous observations in heavily deformed and annealed materials [6,25-27]. In the center layer, where the initial distribution of orientations in the deformed state was more varied, the removal of boundaries with small spacings leads to a smaller change in the HAB fraction. As a result, material with initially similar fractions of HABs in the different layers after coarsening contains remarkably different HAB fractions in the center and subsurface layers (Fig.5a). 


\subsection{Texture changes due to coarsening}

The observed texture changes during coarsening, in particular, the loss of the Bs texture component in both the center and subsurface layers, and the significant increase in the fraction of the $\mathrm{Cu}$ component in the subsurface layers can also be understood based on the process of removal of lamellae with small spacings. After deformation the smallest lamellae will comprise a wide range of texture components. The texture change during coarsening will however depend on the volume fraction (and the associated spatial distribution), combined with the multiplicity and the average spacing for each texture component. For example, due to the low volume fraction of the Bs orientation, a Bsoriented lamella has a very low probability of having neighbors of another symmetric Bs variant. Since Bs-oriented bands are also characterized by a smaller average HAB spacing compared to bands of the other rolling texture components, coarsening by TJ motion results in a preferential removal of volumes with the Bs orientation, thus leading to a decrease in the fraction of this component. This process accounts for the observed loss of the Bs component in our material, and may provide an additional explanation for the previous findings of Zahid et al. [6] and Quadir et al. [25], who also observed elimination of the Bs component in their annealing experiments.

In contrast to the Bs-oriented lamellae typically surrounded by bands of other orientations, for a narrow S-oriented lamella located in the center layer there is a high (more than 50\%) probability of at least one neighbor being of another symmetric $\mathrm{S}$ orientation, so that on average coarsening leads to no change in the fraction of the $\mathrm{S}$ component (see Fig.6a). In each subsurface layer, small lamellae of any other orientation than a dominant $\mathrm{Cu}$ component tend to be consumed during coarsening by lamellae of the dominant component, and the fraction of the $\mathrm{Cu}$-oriented material increases significantly (Fig.6b).

\subsection{Influence of recovery on recrystallization behavior}

The large changes in the microstructure and texture during recovery are very important for determining the subsequent recrystallization behavior. In the center layer, where the rolling texture is represented by 4 symmetric variants of the $\mathrm{S}$ component, 2 variants of the $\mathrm{Cu}$ component and 2 variants of the Bs component (see Fig.3a), and where 
the fraction of HABs in the recovered microstructure is still sufficiently large, a large number of nuclei can form, thus resulting in a fine recrystallized grain size. In contrast, each subsurface layer of the recovered material is characterized by the presence of one dominant orientation, with fewer crystallites surrounded by highly mobile HABs. Correspondingly, a smaller number of successful recrystallization nuclei can be produced in these layers, which results in a larger final grain size than that in the center (see Fig.9).

It has been shown that as nuclei with orientations of the rolling texture grow into an environment with similar orientations, their growth is on average slower (orientation pinning effect $[28,29])$ compared to nuclei with orientations substantially different from those in the rolling-texture matrix. In heavily rolled aluminum alloys such non-rolling texture orientations have often been observed in the vicinity of coarse particles and therefore particle deformation zones frequently become an important source of viable nuclei in particle-rich $\mathrm{Al}$ alloys [17,30-36]. In particular, the $\mathrm{P}$ and Cube $\mathrm{ND}_{\mathrm{ND}}$ texture components are typically attributed to PSN in industrial 3xxx-series alloys when boundary migration is hindered by precipitation [33-36]. However, in commercial purity aluminum, where the frequency of large particles is comparatively low [37,38], and where the extent of precipitation is much less than in 3xxx-series $\mathrm{Al}$ alloys, these components are typically very weak in the annealing texture even for samples deformed to strains as high as $3-4[8,37,39]$.

In our previous work [8], the development of pronounced $\mathrm{P}$ and Cube $\mathrm{ND}_{\mathrm{N}}$ components in AA1050 annealed after ultrahigh-strain rolling, as compared to that after lower strains, has been attributed to an increased frequency of sites able to produce PSN and to the increased importance of orientation pinning. Orientation pinning appears especially important in the two subsurface layers, where the recovered matrix in each layer is strongly dominated by one $\mathrm{Cu}$ component. Our EBSD measurements show that in these layers the fraction of low angle misorientations between $\mathrm{Cu}$-oriented nuclei (defined as crystallites greater than $20 \mu \mathrm{m}^{2}$ ) and the surrounding matrix in the sample annealed for 10 minutes is $55 \%$. Therefore, the growth of these nuclei in the subsurface layers is likely to be hindered by orientation pinning effects. In contrast, nuclei with orientations of P, Cube $e_{N D}$ and "random" components will be mostly unhindered by such effects. 
The results of our investigation show that the microstructure developed during coarsening is strongly influenced by the initial spatial arrangement of different texture components in the deformed material. The observation that significant changes can take place in the microstructure during the period of initial coarsening is also of importance with regard to the ongoing discussion about the existence of a transition in annealing behavior from discontinuous to continuous recrystallization. Although it has been reported in a number of studies that such a transition can be related to the fraction of HABs in the deformed microstructure (typically quoted as occurring for fractions above $65-70 \%[2-5])$, the results of the present study highlight the fact that the spatial distribution of the different boundary types is also very important. It is reasonable to suggest that since the initial HAB fraction may change dramatically during recovery, information about the fraction of HABs in the as-deformed microstructure may not be sufficient to predict the course and type of subsequent recrystallization.

Our findings may therefore have significant implications for modeling of recrystallized microstructures and annealing textures. In particular, it is suggested that attempts to predict the type of recrystallization and resulting microstructures and textures should take into account sample scale variations in the spatial distribution of different texture components and their evolution during coarsening. Moreover, it may be also possible to utilize these variations in annealing behavior to achieve final microstructures with different combinations of grain sizes, extent of recrystallization, and textures in the center and subsurface layers. Such a possibility may guide future research and development with the objective of designing materials and processing routes to yield samples with tailored microstructures to achieve optimized combinations of strength and ductility.

\section{Conclusions}

Recovery and recrystallization have been studied in commercial purity aluminum cold rolled to an ultrahigh strain $\left(\varepsilon_{\mathrm{vM}}=6.4\right)$ and isothermally annealed at $300^{\circ} \mathrm{C}$. The following conclusions are drawn from this study. 
1. The deformed material consists of the three layers: two opposite subsurface layers and a center layer. Microstructures in each layer contain similar fractions of HABs and have similar lamellar boundary spacings, but have very different textures and different spatial arrangements of the rolling texture components.

2. During very short annealing recovery takes place in the deformed microstructure resulting in a significant increase in the spacing between lamellar boundaries along with a pronounced reduction in the fraction of HABs. These changes are considered to arise due to shrinkage of two-sided lamellar volumes, which proceeds via lateral motion of triple junctions. The recovery process is similar in the center and subsurface layers, but because of the different initial spatial arrangement of the texture components in these layers, the loss of HABs is significantly greater in the subsurface layer as compared to the center layer.

3. Further annealing leads to discontinuous recrystallization, which occurs differently in the center and subsurface layers. In the center layer recrystallization proceeds more rapidly and with a larger frequency of nuclei, resulting in a smaller recrystallized grain size. In contrast, pronounced recrystallization in the subsurface layers is delayed and the recrystallized grain size is larger than in the center.

4. The changes taking place during recovery are very significant in determining the subsequent recrystallization behavior in terms of the recrystallized grain size and texture. The observation of a large decrease in the fraction of HABs during recovery suggests that the value of this parameter in the deformed structure may not be a sufficient criterion for prediction of whether subsequent recrystallization will occur in either continuous or discontinuous manner.

\section{Acknowledgements}

The authors gratefully acknowledge the support from the Danish National Research Foundation (Grant No. DNRF86-5) and the National Natural Science Foundation of 
China (Grant No. 51261130091) to the Danish-Chinese Center for Nanometals. Dr. T.B.

$\mathrm{Yu}$ is acknowledged for useful discussions.

\section{References}

[1] Valiev RZ, Islamgaliev R.K., Alexandrov I.V: Progr. Mater. Sci., 2000;45:103.

[2] Oscarsson A, Ekström H-E, Hutchinson B: Mater. Sci. Forum, 1993;1113-115:177.

[3] Oscarsson A, Hutchinson B, Nicol B, Bate PS, Ekström H-E: Mater. Sci. Forum, $1994 ; 157-162: 1271$

[4] Humphreys FJ. Acta Mater. 1997;45:4231.

[5] Jazaeri H, Humphreys FJ. Acta Mater. 2004;52:3251.

[6] Zahid GH, Huang Y, Prangnell PB. Acta Mater. 2009;57:3509.

[7] Yu TB, Hansen N, Huang X. Proc. R. Soc. A 2011;467:3039.

[8] Mishin OV, Juul Jensen D, Hansen N. Metall. Mater. Trans. A 2010;41:2936.

[9] Truszkowski W, Krol J, Major B. Metall. Trans. A, 1980;11:749.

[10] Schoenfeld SE, Asaro RJ. Int. J. Mech. Sci. 1996;38:661.

[11] Mishin OV, Bay B, Juul Jensen D. Metall. Mater. Trans. A 2000;31:1653.

[12] Mishin OV, Bay B, Winther G, Juul Jensen D. Acta Mater. 2004;52:5761.

[13] Choi C-H, Kwon J-W, Oh KH, Lee DN. Acta Mater. 1997;45:5119.

[14] Barlat F, Brem JC, Liu J. Scr. Metal. Mater. 1992;27:1121.

[15] Choi S-H, Barlat F. Scr. Mater. 1999;41:981.

[16] Hansen N. Metall. Mater. Trans. A 2001;32:2917.

[17] Humphreys FJ. Acta Metall. 1977;25:1323.

[18] Gottstein G, Shvindlerman LS. Acta Mater 2002;50:703.

[19] Gottstein G, Shvindlerman LS. Z. Metallkd 2004;95:219.

[20] Czubayko U, Sursaeva VG, Gottstein G, Shvindlerman LS. Acta Mater 1998;46:5863.

[21] Gottstein G, King AH, Shvindlerman LS. Acta Mater 2000;48:397.

[22] Protasova SG, Gottstein G, Molodov DA, Sursaeva VG, Shvindlerman LS. Acta Mater 2001;49:2519.

[23] Gottstein G, Ma Y, Shvindlerman LS. Acta Mater 2005;53: 1535.

[24] Hansen N, Yu T, Mater. Sci. Forum 2012;715-716:374. 
[25] Quadir MZ, Al-Buhamad O, Bassman L, Ferry M. Acta Mater. 2007;55:5438.

[26] Gazder AA, Hazra SS, Pereloma EV, Mater. Sci. Eng A. 2011;530:492.

[27] Tian H, Suo HL, Mishin OV, Zhang YB, Juul Jensen D. J. Mater. Sci. 2013;48:4183.

[28] Juul Jensen D. Acta Metall. Mater. 1995;43:4117.

[29] Doherty R, Progr. Mater. Sci. 1997;432:39.

[30] Engler O, Yang P, Kong XW. Acta Mater. 1996;44:3349.

[31] Engler O, Hirsch J, Lücke K. Acta Metall. Mater. 1995;43:121.

[32] Daaland O, Nes E. Acta Mater. 1996;44:1413.

[33] Vatne HE, Engler O, Nes E. Mater. Sci. Technol. 1997;13:93.

[34] Liu J, Banovic SW, Fields RJ, Morris JG. Metall. Mater. Trans A 2006;37:1887.

[35] Zeng Q, Wen X, Zhai T. Metall. Mater. Trans A 2009;40:2488.

[36] Schäfer C, Gottstein G. Int. J. Mater. Res. 2011;102:1106.

[37] Engler O, Vatne HE, Nes E. Mater. Sci. Eng. A 1996;205:187.

[38] Ekström H-E, Mishin OV, Hamerton RG. Mater. Sci. Forum, 2002;396-402:575.

[39] Juul Jensen D, Hansen N. Metall. Trans. A, 1986;17:253.

Table 1. EBSD data for the cold-rolled sample. "Cu", "S" and "Bs" designate the three standard components of the rolling texture, $\{112\}<111>,\{123\}<634>$ and $\{110\}<112>$, respectively.

\begin{tabular}{lccccccccc}
\hline Layer & $\begin{array}{c}\text { HAB } \\
\text { fraction }\end{array}$ & $\begin{array}{c}\text { Average } \\
\text { boundary } \\
\text { spacing } \\
\text { along ND } \\
(\mu \mathrm{m})\end{array}$ & $\begin{array}{c}\text { Average HAB } \\
\text { spacing along ND } \\
\text { in bands of } \\
\text { different texture }\end{array}$ & \multicolumn{3}{c}{$\begin{array}{c}\text { Fractions of rolling texture } \\
\text { components } \\
\text { components }(\mu \mathrm{m})\end{array}$} \\
\cline { 4 - 11 } & 54 & 0.24 & 0.48 & 0.45 & 0.39 & 28 & 53 & 15 & 96 \\
Center & 56 & 0.23 & 0.53 & 0.35 & 0.23 & 50 & 38 & 4 & 92 \\
\hline
\end{tabular}




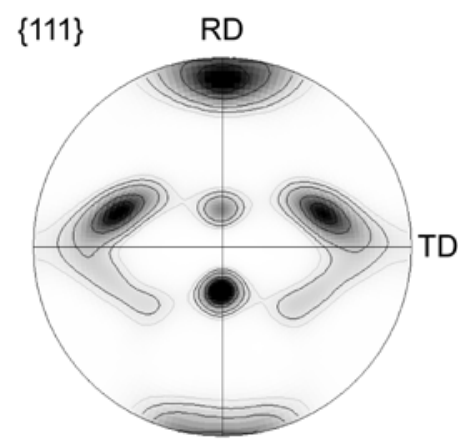

(a)

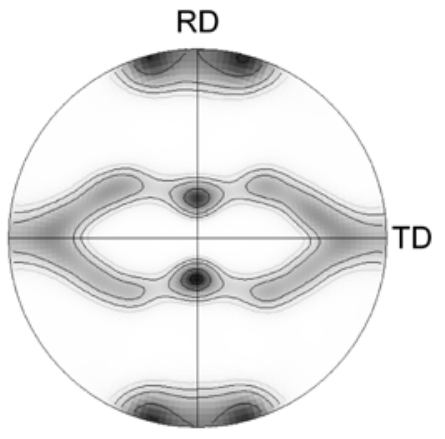

(b)

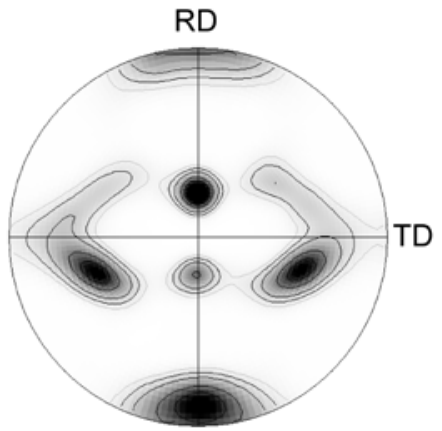

(c)

LEVELS: $\quad \begin{array}{llllll}0.5 & 1.0 & 2.0 & 5.0 & 8.0 & 15.0\end{array}$

Figure 1. $\{111\}$ pole figures showing textures in the as-rolled sample for $(\mathrm{a}, \mathrm{c})$ the two opposite subsurface layers and (b) the center layer.

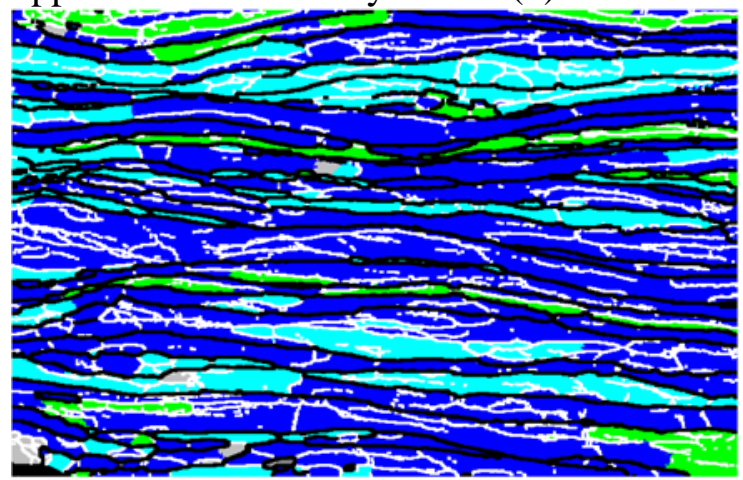

(a)

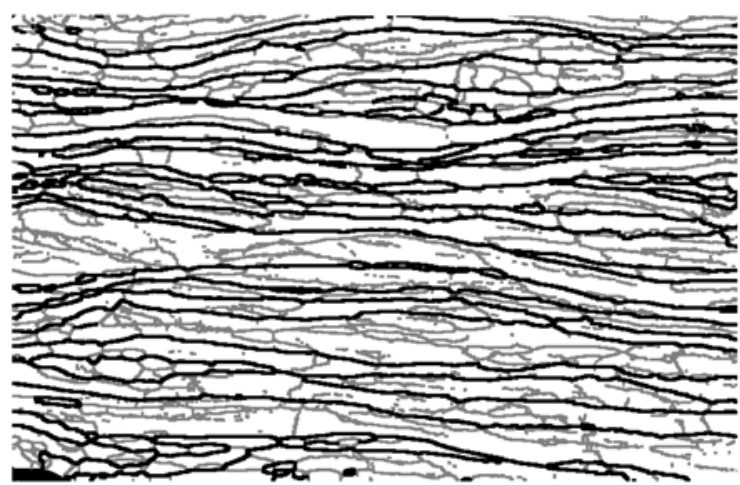

(c)

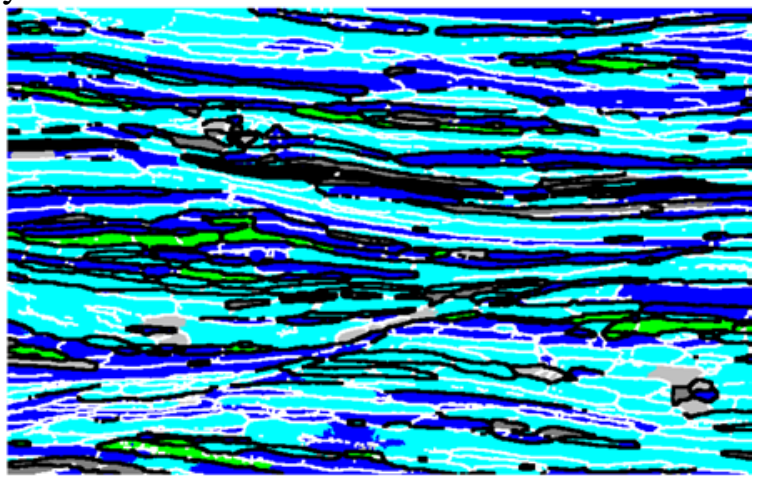

(b)

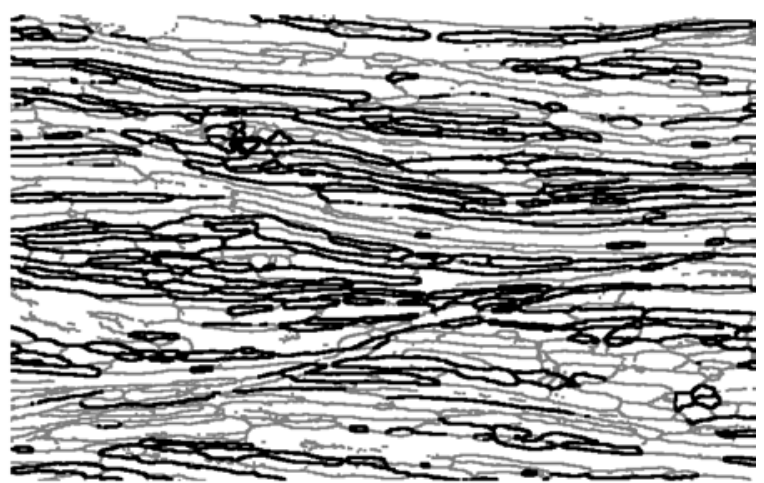

(d)

\section{Cu $\square$ s $\square$ Bs}

\section{$2 \mu \mathrm{m}$}

Figure 2. EBSD maps showing deformation structures in $(a, c)$ the center and (b,d) the subsurface of the as-rolled sample: $(\mathrm{a}, \mathrm{b})$ orientation maps; (c,d) misorientation maps. Orientations that do not belong to any orientation listed in the color code are represented by different shadings of gray in $(a, b) .1 .5-15^{\circ}$ misorientations are shown by white lines in $(a, b)$ and by gray lines in (c,d). Black lines indicate HABs. 
CENTER

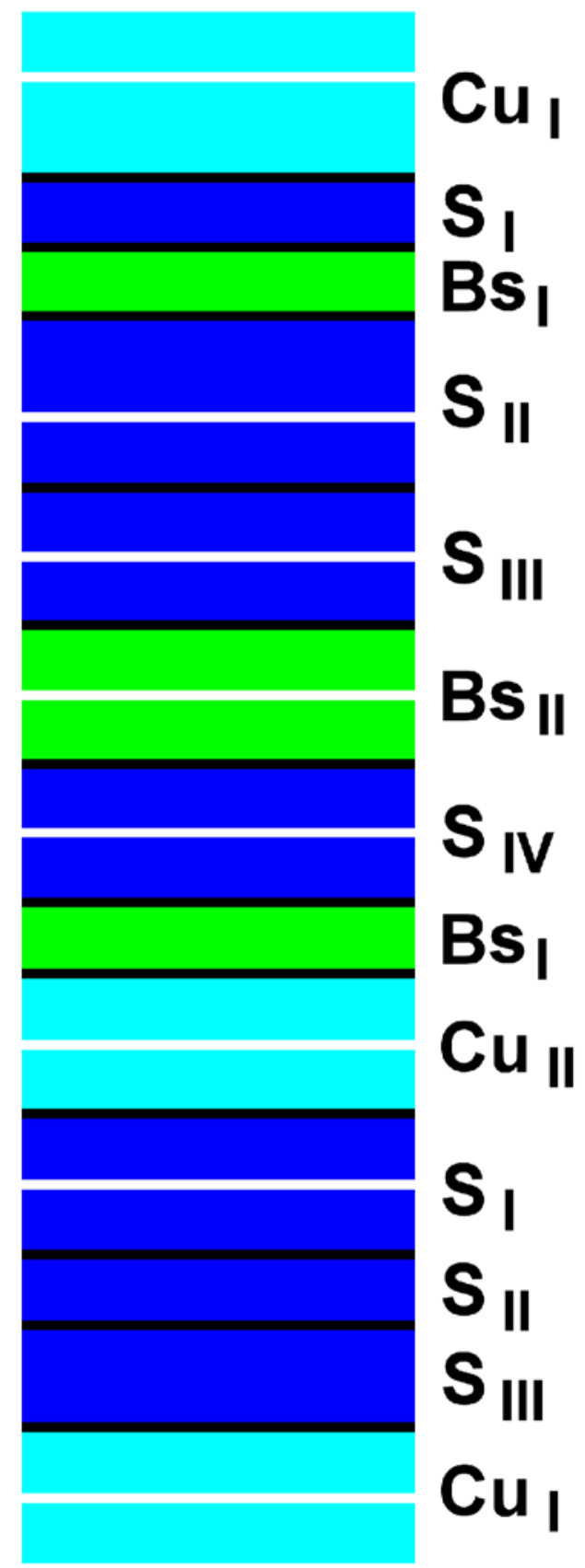

\section{SUBSURFACE}

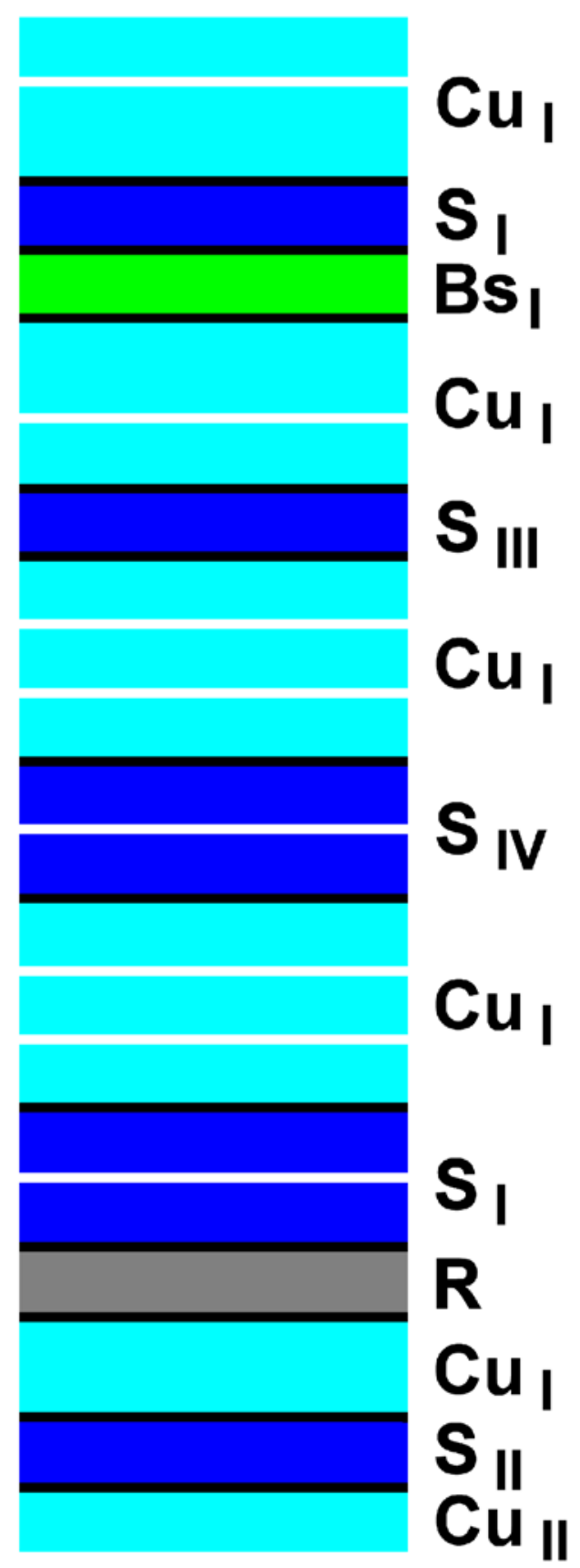

Figure 3. A schematic illustration of the spatial arrangement of different texture components in the center and subsurface layers. Broad texture bands in the center layer may be composed of several symmetric variants (marked with Roman numerals) of the dominant S-component, whereas in the subsurface broad texture bands consist predominantly of a single Cu-texture variant (either $\mathrm{Cu}_{\mathrm{I}}$, as shown in this figure, or $\mathrm{Cu}_{\mathrm{II}}$ in the opposite subsurface layer). " $\mathrm{R}$ " corresponds to a "random" orientation. White and black lines correspond to LABs and HABs, respectively. 


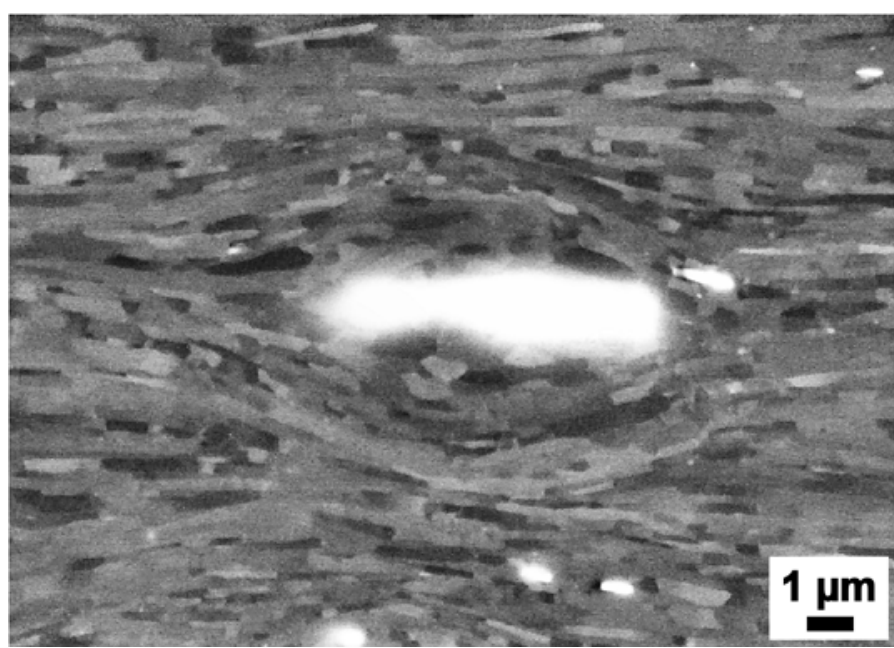

Figure 4. BSE image showing a deformation zone formed around a coarse particle.

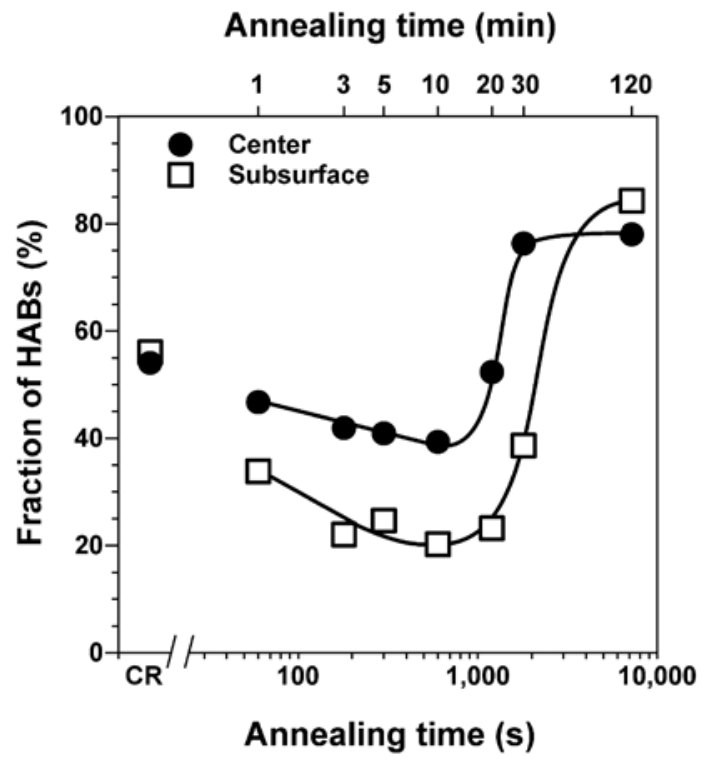

(a)

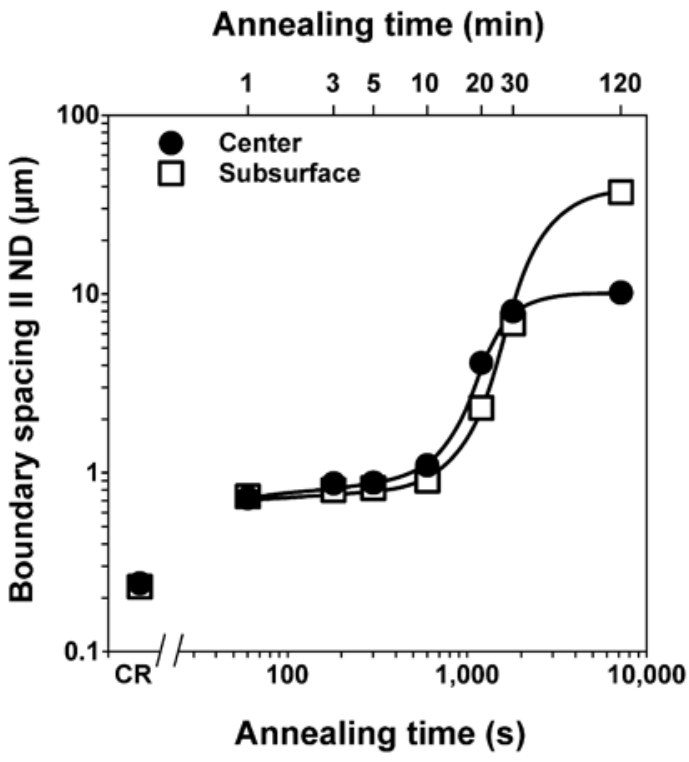

(b)

Figure 5. EBSD data showing the changes in structural parameters during annealing at $300^{\circ} \mathrm{C}$ : (a) the fraction of HABs; (b) the average boundary spacing along the ND. The evolution can be loosely divided into three stages: rapid coarsening (first minute); slow coarsening (up to 10 minutes) and pronounced recrystallization (above 10 minutes). During the coarsening the fraction of HABs decreases in each layer, although this decrease is more pronounced in the subsurface. 


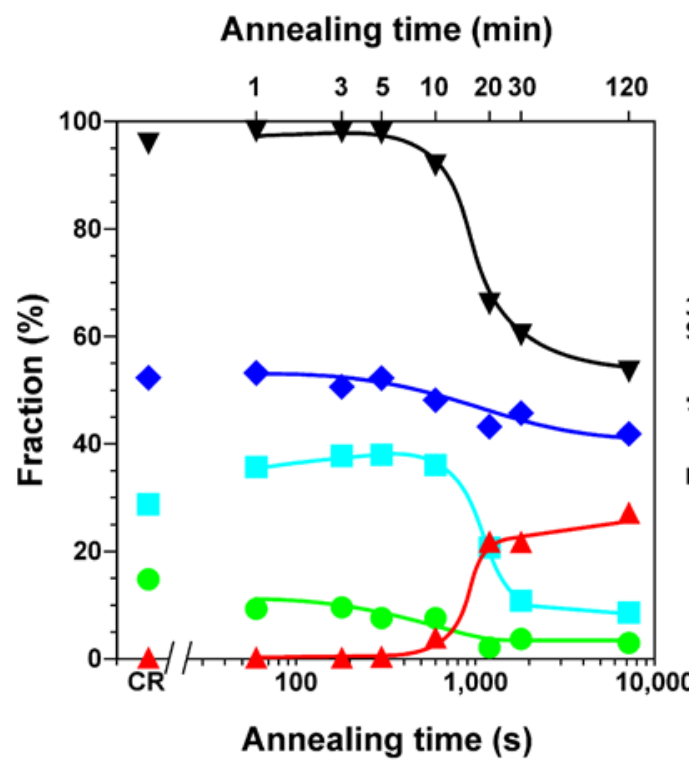

(a)

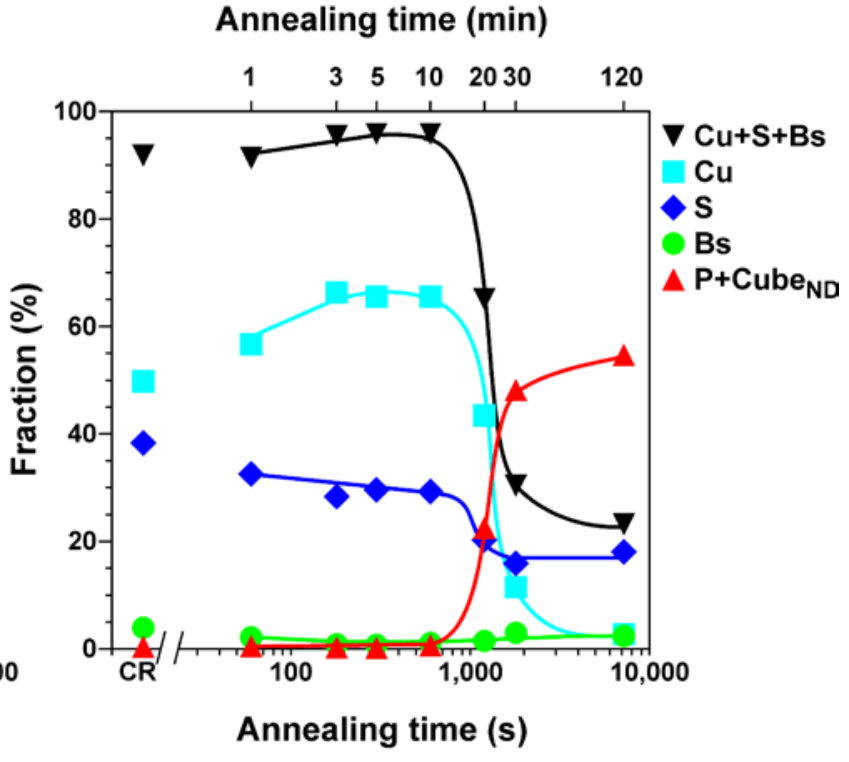

(b)

Figure 6. Effect of annealing at $300^{\circ} \mathrm{C}$ on fractions of different texture components: (a) the center layer and (b) the subsurface layers. In the initial stage of annealing the fraction of the $\mathrm{Cu}$ component becomes very high in the subsurface. In both layers, recrystallization results in a dramatic drop in the fraction of the rolling texture, whereas the $\mathrm{P}$ and Cube $\mathrm{ND}_{\mathrm{N}}$ components become prominent.

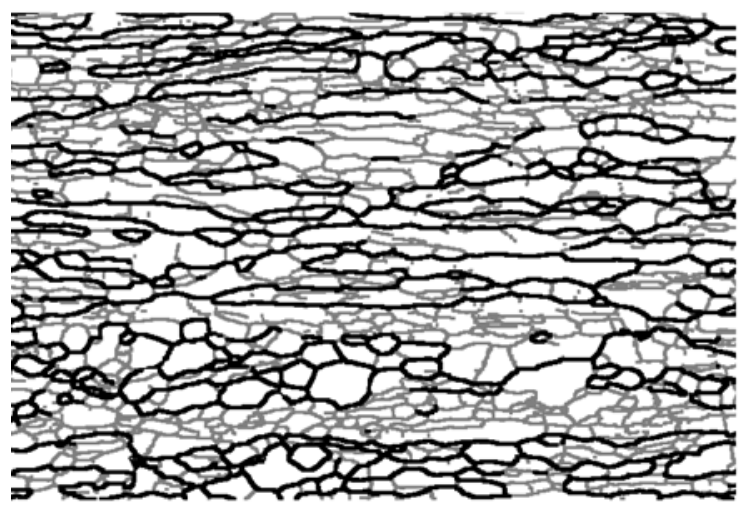

(a)

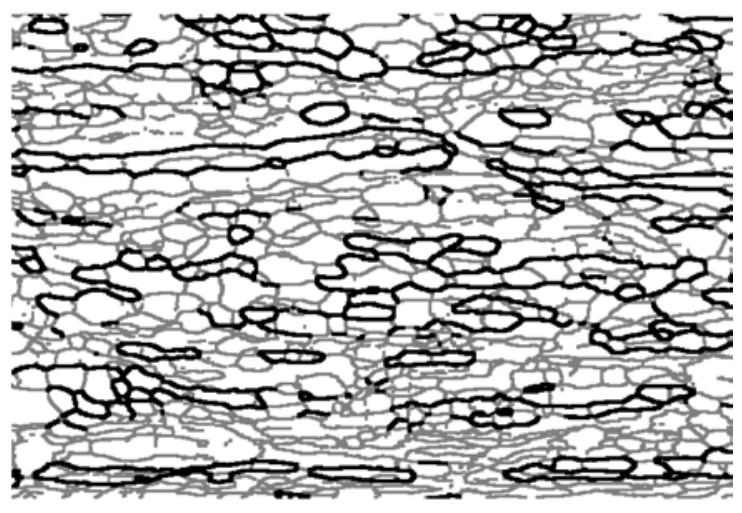

(b)
$10 \mu \mathrm{m}$

Figure 7. EBSD maps representing the microstructure in the sample annealed at $300^{\circ} \mathrm{C}$ for 1 min: (a) center region and (b) subsurface region. Gray lines correspond to $1.5-15^{\circ}$ misorientations. Black lines show HABs. The characteristic lamellar structure formed by cold rolling is largely retained in this microstructure. 


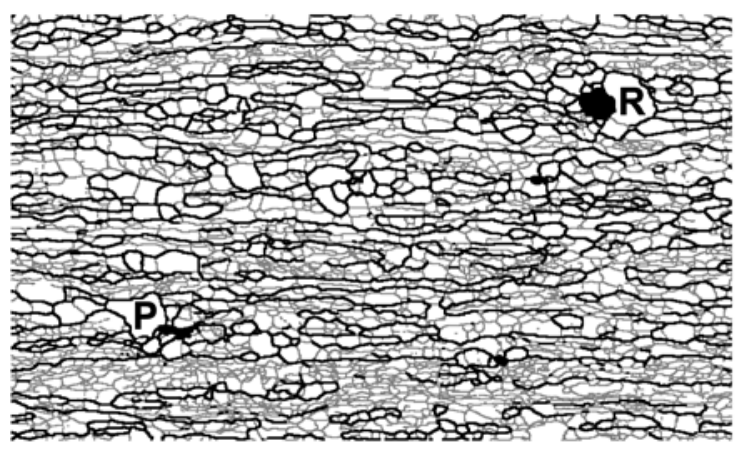

(a)

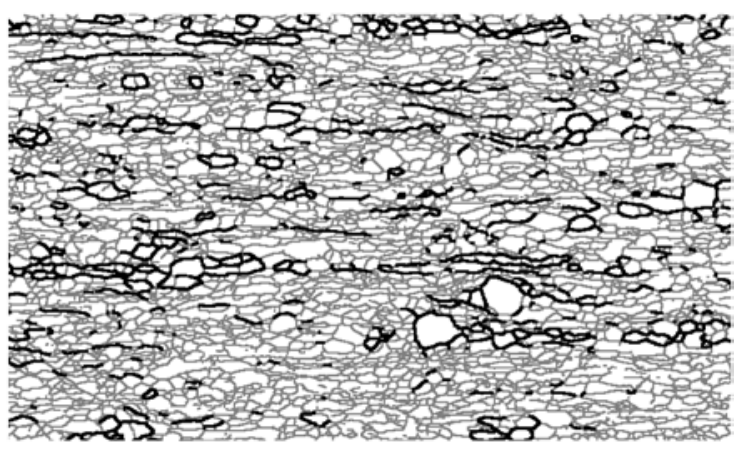

(b)
$10 \mu \mathrm{m}$

Figure 8. EBSD maps illustrating the microstructure in the center and subsurface layers in the sample annealed at $300^{\circ} \mathrm{C}$ for $3 \mathrm{~min}$. The annealing leads to a large reduction in the HAB fraction and to the onset of recrystallization. Nuclei develop both within lamellae and at particles. Letters "P" and " $\mathrm{R}$ " in (a) mark crystallites with either P or "random" orientation nucleated at coarse particles (seen as dark regions). Gray lines correspond to $1.5-15^{\circ}$ misorientations. Black lines show HABs.

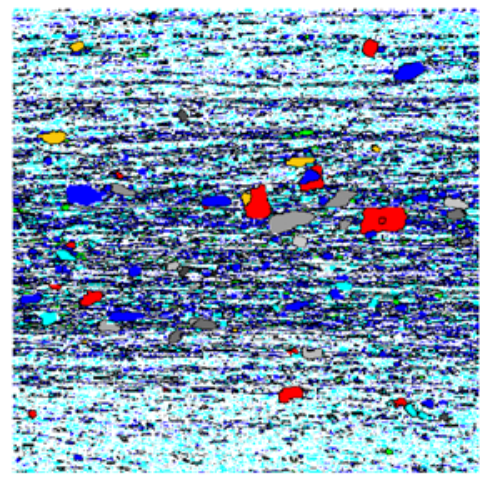

(a)

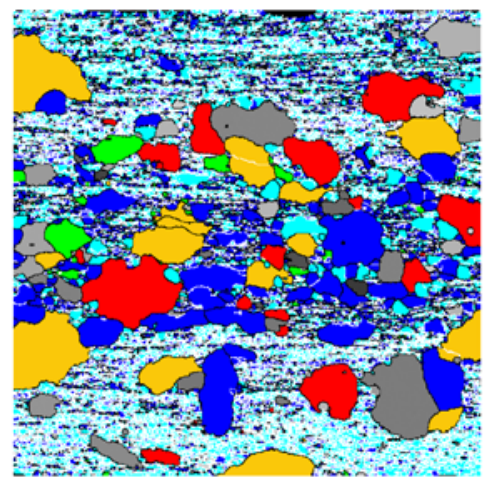

(b)

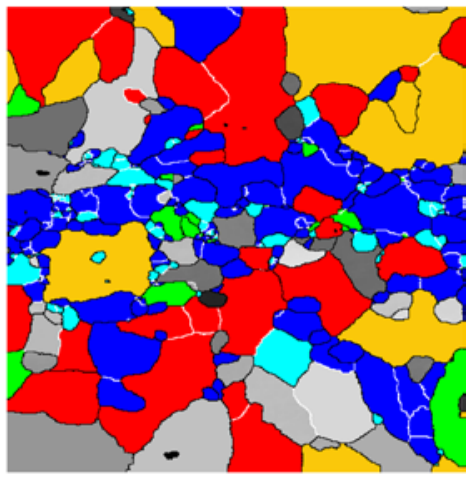

(c)

\section{$\mathrm{Cu}$}

Bs

Cube $_{\mathrm{ND}}$

$100 \mu \mathrm{m}$

Figure 9. Orientation maps showing the microstructure throughout the sample thickness after annealing at $300^{\circ} \mathrm{C}$ for (a) $10 \mathrm{~min}$; (d) $20 \mathrm{~min}$ and (c) $2 \mathrm{~h}$. Orientations that do not belong to any orientation listed in the color code are represented by different shadings of gray. White lines show misorientations $>3^{\circ}$. HABs are depicted by black lines. Significant differences between the center and subsurface layers are seen in the frequency of recrystallized grains and in the final grain size. 


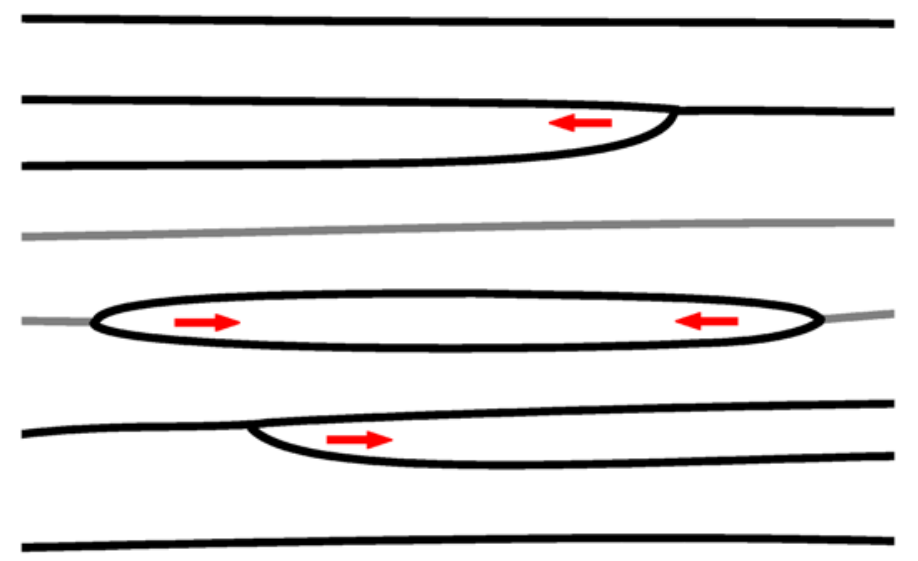

(a)

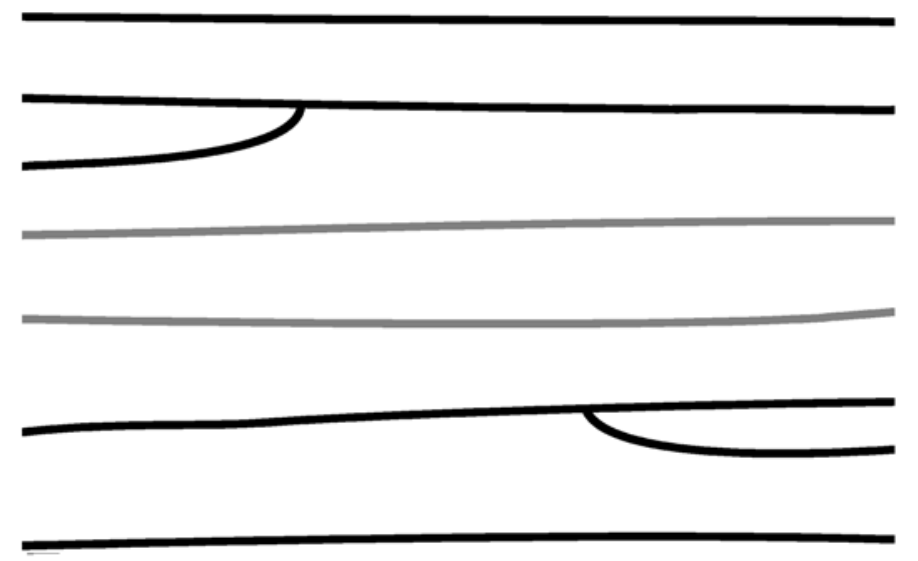

(b)

Figure 10. Schematic showing coarsening via lateral motion of Y-type triple junctions in a deformed lamellar microstructure: (a) initial microstructure; (b) microstructure after TJ motion. Black and gray lines indicate high angle and low angle lamellar boundaries, respectively. In this example, removal of two HABs in the central part of (a) results in the formation of one extra $\mathrm{LAB}$ leading to an increase in the spacing between lamellar boundaries with a concurrent reduction in the frequency of HABs. 


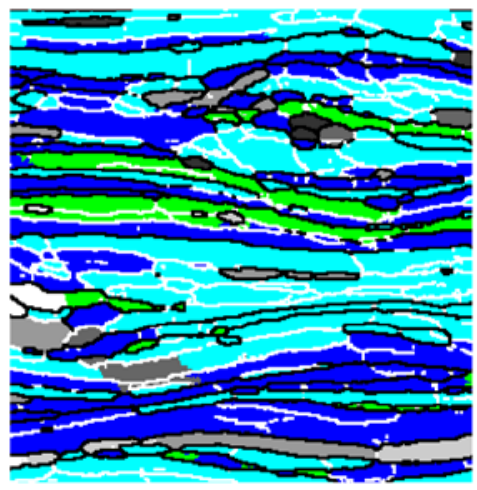

(a)

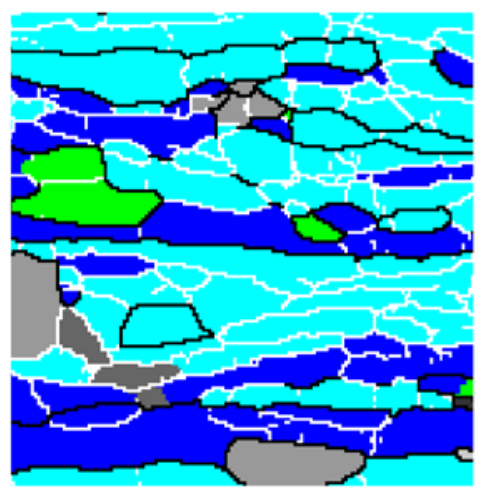

(b)

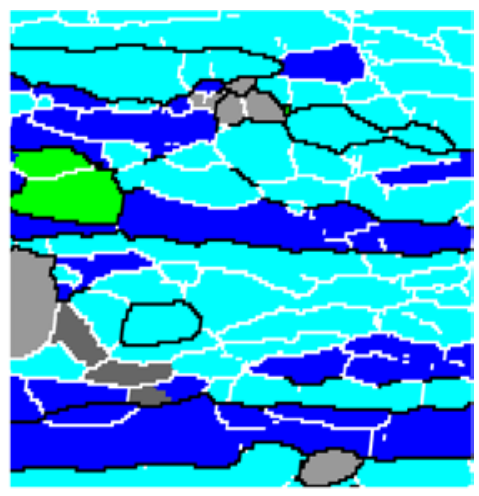

(c)

Figure 11. Orientation maps from the one subsurface region investigated in the cold-rolled condition (a), after $20 \mathrm{sec}$ at $300^{\circ} \mathrm{C} \mathrm{(b)} \mathrm{and} \mathrm{after} 1 \mathrm{~min}$ at $300^{\circ} \mathrm{C} \mathrm{(c).} \mathrm{Orientations} \mathrm{that} \mathrm{do} \mathrm{not}$ belong to any orientation listed in the color code are represented by different shadings of gray. White lines show $1.5-15^{\circ}$ misorientations. HABs are indicated by black lines. During annealing many small subgrains and narrow lamellae delineated by HABs disappear, which results in a large increase in the boundary spacing and LAB fraction, however the lamellar structure is retained. 


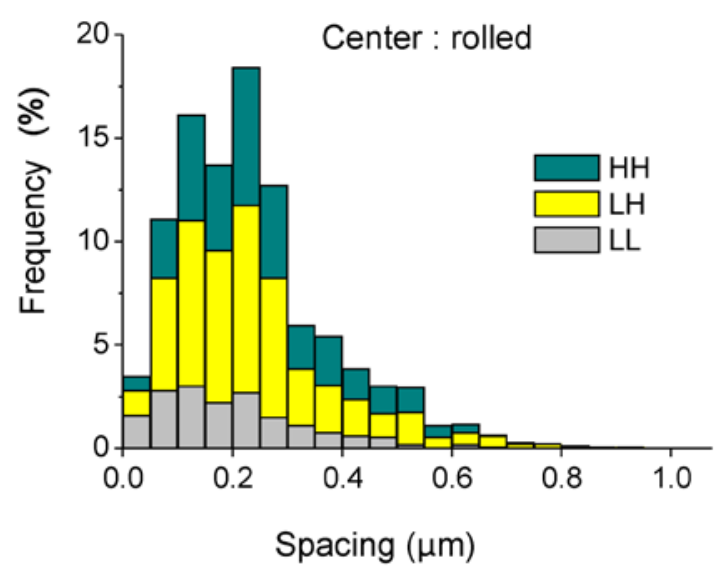

(a)

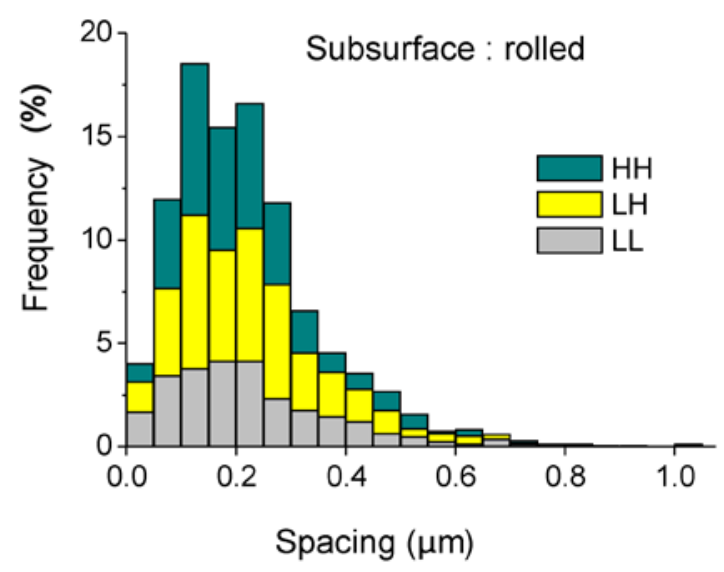

(c)

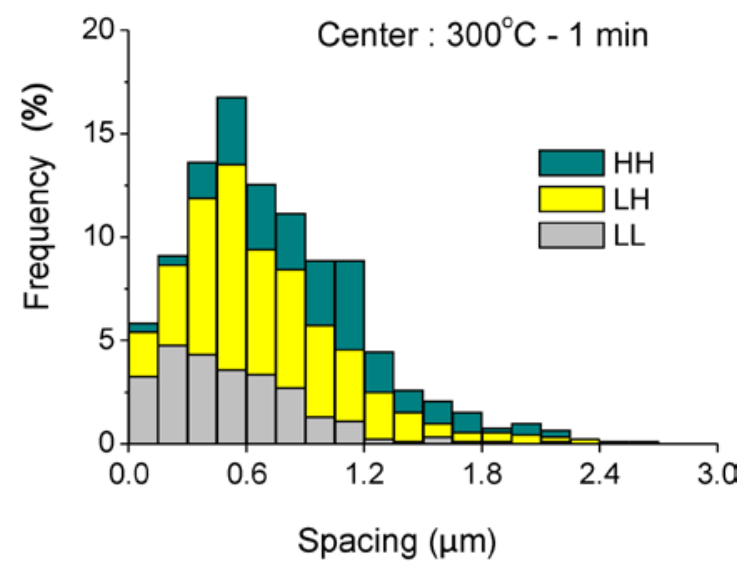

(b)

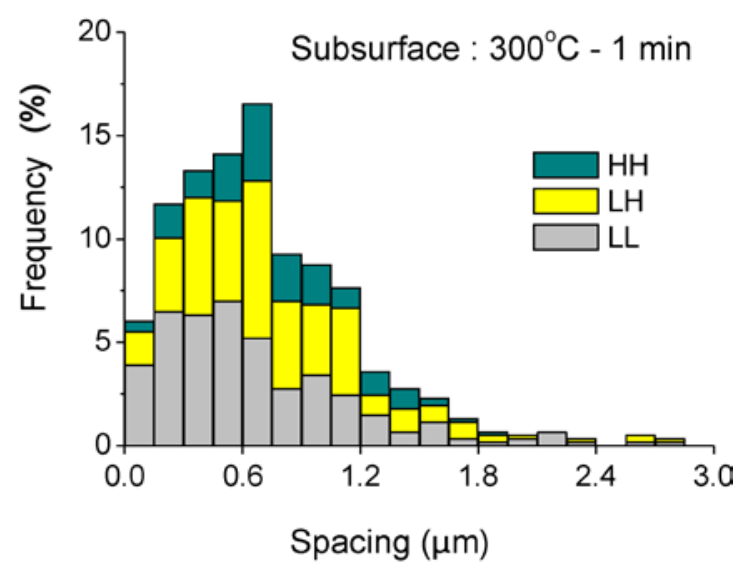

(d)

Figure 12. Distribution of boundary spacings in cold-rolled condition (a,c) and after annealing at $300^{\circ} \mathrm{C}$ for $1 \mathrm{~min}(\mathrm{~b}, \mathrm{~d})$. Distributions for the center and susbsurface layers are shown in $(\mathrm{a}, \mathrm{b})$ and $(\mathrm{c}, \mathrm{d})$, respectively. Different colors correspond to spacings between two adjacent HABs (HH), two adjacent LABs (LL), or one LAB and one HAB (LH). Similar changes in the distributions are seen for the center and subsurface layers. 